\title{
Maternal and Paternal Mental-state Talk and Executive Function in Preschool Children
}

\author{
Joana Baptista ${ }^{1}$, Ana Osório ${ }^{2}$, Eva Costa Martins ${ }^{3}$, Paula Castiajo ${ }^{1}$, \\ Ana Luísa Barreto ${ }^{1}$, Vera Mateus ${ }^{1}$, Isabel Soares ${ }^{1}$ and Carla Martins ${ }^{1}$ \\ ${ }^{1}$ School of Psychology, University of Minho \\ ${ }^{2}$ Mackenzie Presbyterian University \\ ${ }^{3}$ Maia University Institute - ISMAI/CPUP
}

\begin{abstract}
The present study examined the relationship between parents' mental-state talk and preschoolers' executive function. Seventy-two children participated in the present study, as well as their mothers and fathers. When children were enrolled in the second preschool year, mothers' and fathers' use of mental-state references were assessed during a shared picture-book reading task with the child. Later, four months before admission to the first grade, preschoolers' executive function was measured. Hierarchical regression analysis revealed that maternal, but not paternal, mental-state talk was a significant predictor of children's executive function composite, even after accounting for child gender, age, verbal ability, and parental education. When looking at each of the EF components, maternal mental-state talk proved to be a predictor of set-shifting whereas no significant relations emerged with inhibitory control or working memory. These findings add to prior research on parenting quality and executive function in preschoolers.
\end{abstract}

Keywords: executive function; father-child relations; mother-child relations; preschool

\section{Introduction}

Executive function (EF) refers to a set of higher-order cognitive processes that allow for conscious, goal-directed control of thoughts and actions (Diamond, 2013; Zelazo \& Carlson, 2012), including working memory, defined as the ability to maintain and manipulate information for short time periods; set-shifting or the competency to flexibly shift the focus of cognitive set and to adjust behavior accordingly; and inhibitory control, defined as the ability to inhibit an automatic, or dominant, response (Blair \& Ursache, 2013). Although such skills have been found to develop over a long period of time, spanning from the first year of life until adolescence Correspondence should be addressed to Carla Martins, University of Minho, School of Psychology, Campus de Gualtar, 4710-057 Braga, Portugal. Email: cmartins@psi.uminho.pt 
(Blakemore \& Choudhury, 2006; Cuevas \& Bell, 2010; van de Weijer-Bergsma et al., 2010), the most rapid growth in EF occurs during the preschool period (Zelazo, Muller, Frye, \& Marcovitch, 2003), being thus considered a core ability of this developmental phase. In fact, substantial research has documented the crucial role of preschoolers' EF in supporting other important milestones, such as early academic success, including math and literacy achievements (Clark, Pritchard, \& Woodward, 2010; Dilworth-Bart, 2012), as well as the development of sociocognitive skills, namely theory of mind, social and moral competence, and emotion regulation (Carlson, Mandell, \& Williams, 2004; Hughes, \& Ensor, 2011; Kochanska, Murray, \& Coy, 1997).

Despite the aforementioned research highlighting the importance of EF skills for optimal development, less attention has been given to the social determinants of such abilities. There is a good deal of evidence that EF is inextricably linked to the prefrontal cortex (Moriguchi \& Hiraki, 2013), a region of the neocortex not fully mature until the end of adolescence (Giedd, 2008), and therefore, especially sensitive to environmental inputs (Huttenlocher, 2002). Given such close connections between $\mathrm{EF}$ and the slow-developing prefrontal brain, a recent body of research has begun to suggest that the quality of early family and relational experiences are a central mechanism for the development of EF abilities. Although much of the research has been focused on the contribution of more distal processes, including family socioeconomic status, and parental education (Ardila, Rosselli, Matute, \& Guajardo, 2006; Rochette \& Bernier, 2014), recent studies have noted that proximal social relational factors may be of particular interest for understanding individual differences in EF, including the quality of both maternal and paternal behavior during parent-child interactions (for a review, see Moriguchi, 2014). This is the subject addressed in the present article.

According to Carlson (2003), three distinct dimensions of parenting are likely to contribute to the development of EF: (1) two behavioral dimensions, namely parental scaffolding (i.e., the ability of the caregiver to offer children ageappropriate problem-solving strategies) and sensitivity (i.e., the ability of the caregiver to respond to the child's signals in a consistent and appropriate manner), and (2) a verbal dimension, referring to the tendency to use mental-state terms while talking to the child. Indeed, the contributions of parental scaffolding (Bibok, Carpendale, \& Müller, 2009; Hammond, Müller, Carpendale, Bibok, \& LibermannFinestone, 2012; Landry, Miller-Loncar, Smith, \& Swank, 2002; Lowe et al., 2014) and sensitivity (Blair et al., 2011; Towe-Goodman et al., 2014) for the development of EF skills have been the focus of recent empirical interest. However, less attention has been given to the role of parental mental-state talk-referring to the child's, one's own and others' desires, emotions, and cognitions - when dialoguing with the child. The work of Bernier, Carlson, and Whipple (2010), as well as of Bernier, Carlson, Deschênes, and Matte-Gagné (2012) serve as notable exceptions. These investigators measured several indices of parenting, when children were 12 and 15 months old, finding that maternal use of mental-state references, along with scaffolding and sensitivity, were related to child EF tasks at 18 and 26 months (Bernier et al., 2010), and again at three years of age (Bernier et al., 2012), even after accounting for maternal education and child cognitive functioning. Furthermore, although maternal scaffolding was considered to be the strongest predictor of $\mathrm{EF}$ at 18 and 26 months of age, the authors found that maternal use of mental-state comments better explained increases in child EF performance between those two 
ages (Bernier et al.). The authors argued that mothers' use of mental-state references is a vital parenting dimension for the development of EF, because it supplies children with the necessary verbal tools for them to reflect and be aware of their own responses (Bernier et al.).

This last assumption is consistent with the theoretical framework of human learning advanced by Vygotsky (1934/1986). Vygotsky acknowledged that the regulatory speech of caregivers, during early interpersonal interactions, would be eventually internalized by the child, and the words would become mental tools for the offspring to manipulate his/her own thoughts and behavior, allowing, thus, the progression from external to internal forms of self-regulation (Kopp, 1982; Vallotton \& Ayoub, 2011). Here, we advance that parental talk about mental states, including desires, thoughts, and emotions, may be a critical component of the caregivers' speech, particularly influential for the development of child EF abilities. Being exposed to caregivers' mental-state talk in everyday interactions, children have the opportunity to learn words to express their desires, needs and feelings, which may, in turn, aid them in regulating their thoughts, emotions, and behaviors, according to the demands of novel or complex situations (Hughes, 2011; Vallotton \& Ayoub, 2011).

Despite these theoretical accounts, and the undoubted importance of the pioneer investigation cited above, it is important to appreciate that the research in this field is still characterized by a paucity of studies focused on the links between parental mental-state talk and child EF during the preschool years. In addition, it is also worth noting that the contribution of fathers' mental-state talk to the development of EF skills remains to be investigated, as most studies on parenting and EF have been focused on mothers. However, considering that fathers have become more involved in caring for their children in recent decades, research on the effects of proximal social relational factors for children's EF should incorporate the role of fathers' parenting.

Indeed, there is reason to believe that the quality of paternal care may independently contribute to the development of EF abilities. In line with this premise, the work of Towe-Goodman and colleagues (2014) is worth mentioning. These investigators measured both maternal and paternal parenting quality, finding that fathers' sensitive and supportive behaviors, assessed when children were 24-months old, were a significant predictor of child EF at three years of age, even after accounting for the quality of concurrent and prior maternal care. These results have been recently supported by Meuwissen and Carlson (2015) who measured fathers' autonomy support and control in a dyadic play task with their three-year-old children, and concluded that fathers' controlling parenting was concurrently and inversely related to their children's EF skills, above and beyond family income and child verbal ability.

Notwithstanding such evidence stressing the importance of the quality of father-child interaction for the development of EF, less is known about the independent role of fathers' use of mental-state terms. This lack of research is remarkable, especially when considering recent studies showing that paternal talk in interaction with the child may be particularly influential for healthy child development. For example, LaBounty, Wellman, Olson, Lagattuta, and Liu (2008) revealed that both maternal and paternal talk, assessed in terms of the usage of mental-state terms during a parent-child picture-book task, influenced the development of their offsprings' socio-cognitive abilities, most notably preschoolers' emotion 


\section{Joana Baptista, Ana Osório, Eva Costa Martins et al.}

understanding, and theory of mind. More recently, similar findings were observed by Lundy (2013) showing that, not only mothers', but also fathers', use of mentalstate comments were positively related to their four-year-olds' theory of mind. Interestingly, all of these socio-cognitive abilities have also been found to be linked to EF skills. For instance, Carlson et al. (2004) found a significant, robust, relation between EF performance and theory of mind at 39 months of age, and Martins, Osório, Veríssimo, and Martins (2014) reported that set-shifting was a significant predictor of emotion understanding, in a sample of preschool age children.

In light of the above, the present report seeks to examine the putative contributions of both maternal and paternal use of mental-state references (desires, emotions, and cognitions) in interaction with the child to EF, in a sample of preschoolers, while controlling for parental education and child age and gender, as each of these factors have been linked to EF skills (Ardila et al., 2005; Brocki \& Bohlin, 2004; Meuwissen \& Carlson, 2015). Moreover, given that studies have suggested consistently that EF is associated with child verbal ability (Fuhs \& Day, 2011; Müller, Zelazo, \& Imsirek, 2005), which in turn may be linked to mothers' and fathers' talk while interacting with the child (Deckner, Adamson, \& Bakerman, 2006; Fivush, Haden, \& Reese, 2006), the current study also aims to clarify whether maternal and paternal mental-state talk are predictive of EF, even after taking child verbal ability into account as an important control variable, something that remains to be investigated. In doing so, the current research is the first to analyze separately both mothers' and fathers' use of mental-state references in interaction with the child, to uncover unique and common influences of maternal and paternal talk on the development of EF skills during the preschool period, a critical phase for the maturation of such abilities (Garon, Bryson, \& Smith, 2008). In line with previous empirical evidence, we hypothesize that both maternal and paternal mental-state talk during a parent-child interaction will significantly predict child EF performance.

\section{Method}

\section{Participants}

Seventy-seven 4.5-year-old children (38 girls, 49.4 percent), were recruited in childcare centres in northern Portugal, for participation in a longitudinal study on the developmental predictors of school readiness. For the present investigation, data were available for 72 children (33 girls, 45.8 percent) (four cases were excluded because there was no assessment of maternal or paternal use of mental-state references, and for one case there were no data on children's EF; please see Measures section). The first assessment (T1) occurred when children were between 53 and 60 months $(M=55.04, S D=1.54)$. Children were reassessed four months before school entry (T2), when they were 63-76 months of age $(M=69.51, S D=3.09)$. The majority came from two-parent families $(n=61,84.7$ percent) with two or more children ( $n=48,66.7$ percent). All children were Caucasian, except one who was Asian. Participants also included the mothers who were between 26 and 46 years $(M=36.69, S D=3.50)$, and the fathers who were between 25 and 61 years of age $(M=38.58, S D=6.19)$. One mother (1.4 percent) and 10 fathers (13.9 percent) had not completed high school, 13.9 percent $(n=10)$ of the mothers and 27.7 percent $(n=20)$ of the fathers had obtained a high school diploma, and the 
remaining had an undergraduate (mother: $n=49$, 68 percent; fathers: $n=30,41.7$ percent) or graduate degree (mothers: $n=12,16.7$ percent; fathers: $n=12,16.7$ percent).

\section{Procedure}

At T1, when children were enrolled in the second preschool year, mothers and fathers were invited to participate with their children in an observation session in a university laboratory setting, to assess maternal and paternal use of mental-state references. Mother and father were assessed in two different, independent, sessions. Parents also completed a socio-demographic questionnaire. The second assessment was carried out in the third, and final, preschool year, four months before children's entry in primary school. Children were tested at the preschool in which they were enrolled or in a university laboratory setting, to assess their EF and verbal ability. In Portugal, where the research reported herein was conducted, preschool education is offered to children between the ages of three to five years. In the year when children become six years of age they enroll in primary school in September. At both time points, mothers and fathers were first explained the purposes of the study as well as the detailed procedures, and gave their written informed consent for their own and their children's participation.

\section{Measures}

\section{Assessments at T1: Second Preschool Year}

Maternal and paternal mental-state talk. Maternal and paternal use of mental-state references were assessed using one of two wordless picture books, namely Frog where are you? (Mayer, 1969) and Frog on his own (Mayer, 1992). Mothers and fathers were asked to tell the story to their children based on the book's pictures. The assignment of either book was counterbalanced. The motherchild and father-child interactions were videotaped, transcribed and then coded to assess references to mental states. References were coded into one of the following mutually exclusive categories: (1) desires (e.g., like, dislike, want); (2) cognitions (e.g., think, know, imagine); and (3) emotions (e.g., happy, sad, angry). Similar to previous studies, utterances serving only as conversational devices (e.g., 'I don't know'), or which were repetitions of own or other's utterances were not coded (Jenkins, Turrell, Kogushi, Lollis, \& Ross, 2003; Ruffman, Slade, \& Crowe, 2002). Each participant received a final score of mental-state talk, consisting of the overall mental state references from all three categories. To control for differences in verbosity, maternal, and paternal mental-state talk was calculated as a proportion of the total number of words, from all three categories, used during the interaction. Inter-rater reliability was assessed by computing the intra-class correlation coefficients for 22 percent $(n=16)$ of mother-child and father-child interactions, which were independently coded by two trained raters. Intra-class correlations for the three types of mental references ranged between $r_{\mathrm{ICC}}=.89$ and $r_{\mathrm{ICC}}=.99$, regarding mother-child interaction, and between $r_{\mathrm{ICC}}=.97$ and $r_{\mathrm{ICC}}=.99$, with respect to father-child interaction.

\section{Assessments at T2: Four Months Before School Entry}

Executive function. EF was measured using three tasks designed to assess inhibitory control, working memory, and set-shifting. All of these tasks have been 
used extensively to assess preschoolers' EF (e.g., Carlson, 2005; Wanless et al., 2011).

(1) Inhibitory control was assessed using the Head-Toes-Knees-Shoulders task (HTKS; Ponitz, McClelland, Matthews, \& Morrison, 2009), a structured observation requiring children to perform the opposite of a dominant response to different oral commands. The HTKS task includes 20 test trials. Children are initially instructed to respond in an unusual manner to a two rules (head/toes) command (items 1-5; e.g., if the experimenter says 'Touch your head', the correct answer would be for the child to touch his or her toes), following two novel (knees/shoulders) commands (items 6-10; e.g., if the experimenter says 'Touch your knees', the correct answer would be for the child to touch his or her shoulders). Then, task complexity increases by asking children to respond to one of four commands (head/toes/knees/shoulders) (items 11-20). Each of the 20 items was scored with 0 for an incorrect response, 1 for a self-correct response, or with 2 for a correct response. The total score ranges from 0 to 40, with higher scores indicative of higher levels of inhibitory control.

(2) Working memory was assessed using the Backward Digit Span task (BDS; Davis \& Pratt, 1995). In the BDS, children are invited to verbally repeat in reverse order sequences of single-digit numbers. Following a two-digit practice trial, children are given two trials for each test sequence, until they fail two consecutive trials of a given length. The highest level of success is recorded.

(3) To assess set-shifting, the Executive Function Scale for Early Childhood (Carlson \& Schaefer, 2012) was used, which consists of an adaptation of the Dimensional Change Card Sort task (Frye, Zelazo, \& Palfai, 1995; Zelazo, 2006). In this task, children are required to sort a series of bivalent cards into boxes with target cards on them. The sorting cards (e.g., red star and blue car) match each target card (e.g., a blue star and a red car) on exactly one dimension. The scale offers seven distinct phases of complexity. For five-year-old children, the task begins in the fifth phase, in which participants are asked to sort the cards based on two dimensions, specifically by color or shape, according to the instructions of the experimenter; thereby requiring that the cards be sorted into opposite boxes (10 items). In the sixth phase, children are required to sort according to another dimension (border vs. non-border); if a black border is presented in the card, children should sort according to color, but if there is not, children should sort according to shape (10 items). Finally, in the last phase of the task, children are instructed to reverse the rule, sorting by color if the card has no black border, or sorting by shape if the card has a black border (10 items). Children were considered to have passed each phase when they correctly sorted four or more cards for each condition of that particular phase (e.g., in the fifth phase, four or more correct answers when asked to sort by color and four or more correct answers when asked to sort by shape). When children failed the fifth phase, the experimenter administered the lower difficulty sorting tests in a predetermined order, in which children were asked to sort the cards based on only one dimension (e.g., by color); if children failed the sixth or seventh phase, the task ended. A total final score is calculated based on the sum of the items. The minimum and maximum scores children could attain were 0 and 70, respectively, with higher scores being indicative of higher levels of set-shifting. 
Child verbal ability: receptive vocabulary. Child verbal ability was assessed using the Peabody Picture Vocabulary Test, revised edition (PPVT-R; Dunn \& Dunn, 1981). Children were orally presented with words, and asked to choose from a set of four pictures, which one corresponded to the word previously heard. The coding consists of subtracting the total number of errors made by children during the test from the highest item children reached. Raw scores were used as the final measure of verbal ability as Portuguese norms for this instrument are not yet available.

\section{Results}

\section{Data Analysis}

Data analysis proceeded in a series of steps. First, a principal component analysis was conducted, to create an EF factor. Then, bivariate correlations were examined between the study variables. Finally, regression analyses were computed to examine the contribution of maternal and paternal mental-state talk to the child EF composite and to each of the EF components (i.e., inhibitory control, working memory, and set-shifting), after accounting for the control variables.

\section{Preliminary Analysis}

Reduction of EF Data. The inhibitory control, working memory and set-shifting scores were standardized and submitted to a principal component analysis. This analysis yielded a one-component solution, Eigen value $=1.61$, representing 54 percent of the total variance. Composite loadings were found to be all higher than .50 (.59 for inhibitory control, .78 for working memory, and .81 for set-shifting). In this analysis, the three EF components were low to moderately intercorrelated (inhibitory control and working memory, $r=.20, p=.043$; inhibitory control and set-shifting, $r=.25$, $p=.016$; and working memory and set-shifting, $r=.44, p<.001)$. This result is in line with previous findings, showing that a single factor model best explained the performance on EF tasks among preschoolers, and that a unitary perspective of executive abilities is more appropriate during this developmental period (Wiebe, Espy, \& Charak, 2008; Wieber et al., 2011). Thereby, in the present study, a composite of EF was calculated, consisting of the mean of the standardized scores of the inhibitory control, working memory, and set-shifting tasks. This composite was used in further analysis.

Descriptive Statistics and Bivariate Correlations. Descriptive statistics and correlations between study variables can be found in Tables 1 and 2, respectively. Regarding the relations between child EF and the control variables, results showed that child verbal ability was positively related to the EF composite, as well as to each of the EF individual components, namely inhibitory control, working memory, and setshifting. No significant associations were found between the EF composite and child gender, age, or parental education. However, set-shifting was significantly correlated with age at T2, and working memory with paternal education.

With regard to parenting variables, positive correlations were observed between maternal use of mental-state references and the EF composite. When looking at the bivariate correlations with each of the EF components, maternal mental-state talk was found to be positively related to set-shifting, but not to inhibitory control or working memory. No significant correlations were observed between paternal use of 
Table 1. Descriptive Statistics

\begin{tabular}{|c|c|c|c|}
\hline & $M$ & $S D$ & Min-Max \\
\hline Child age in months (T1) & 55.04 & 1.54 & $53-60$ \\
\hline Child age in months (T2) & 69.51 & 3.09 & $63-76$ \\
\hline Child verbal ability & 114.12 & 18.10 & $48-141$ \\
\hline Maternal education & 2.01 & .57 & $1-3$ \\
\hline Paternal education & 1.75 & .73 & $1-3$ \\
\hline Maternal mental-state references (raw total) & 19.85 & 10.55 & $6-64$ \\
\hline Desires & 2.69 & 2.75 & $0-16$ \\
\hline Cognitions & 9.53 & 6.39 & $1-33$ \\
\hline Emotions & 7.63 & 4.09 & $0-25$ \\
\hline Maternal mental-state references (proportion) ${ }^{\mathrm{a}}$ & .02 & .01 & $.01-.04$ \\
\hline Paternal mental-state references (raw total) & 15.08 & 8.20 & $3-43$ \\
\hline Desires & 2.28 & 2.22 & $0-10$ \\
\hline Cognitions & 6.67 & 4.41 & $0-22$ \\
\hline Emotions & 6.14 & 3.68 & $1-19$ \\
\hline Paternal mental-state references (proportion) ${ }^{\mathrm{a}}$ & .01 & .01 & $.005-.03$ \\
\hline Executive function ${ }^{\mathrm{b}}$ & .04 & .72 & -3.09 to 1.12 \\
\hline Inhibitory control & 33.61 & 5.87 & $6-40$ \\
\hline Working memory & 2.43 & .89 & $0-4$ \\
\hline Set-shifting & $\begin{array}{c}59.44 \\
n\end{array}$ & $\begin{array}{l}10.43 \\
\%\end{array}$ & $11-70$ \\
\hline Gender, girls & 33 & 45.8 & \\
\hline
\end{tabular}

Note. $\mathrm{T} 1=$ Time $1, \mathrm{~T} 2=$ Time 2.

a Significant differences were observed between mothers and fathers in the overall use of mental-state terms, $t=2.97, p=.004{ }^{\mathrm{b}}$ The executive function composite reflects the mean of the standardized scores of the inhibitory control, working memory, and set-shifting task.

mental-state references and child EF. Parental differences were observed in the use of mental-state terms, such that mothers employed more references to mental states in interaction with the child than fathers, $t(71)=2.97, p=.004$ (Table 1).

Main Analysis: Predicting Child EF. A hierarchical linear regression was computed, to investigate the predictors of the EF composite. Given the consistent empirical findings, showing that child gender, age, maternal and paternal education, as well as child verbal ability, are linked to the development of EF skills, all of these variables were included in the first four steps of the analysis, as covariates, even though only verbal ability was found to be significantly related to the EF composite, in this study (see Table 2). Maternal and paternal mental-state talk were then added to the fifth step of the model. According to Table 3, regarding the control variables, only verbal ability emerged as a significant predictor of the EF composite, $\beta=.58$, $p<.001$. The model proved significant, explaining 36 percent of the overall variance in EF skills. Concerning the parenting variables, and as stated earlier, both maternal and paternal mental-state talk were entered simultaneously in the final step of the analysis. The model proved significant, accounting for additional 4 percent of 
Mental-state Talk and Executive Function in Preschoolers

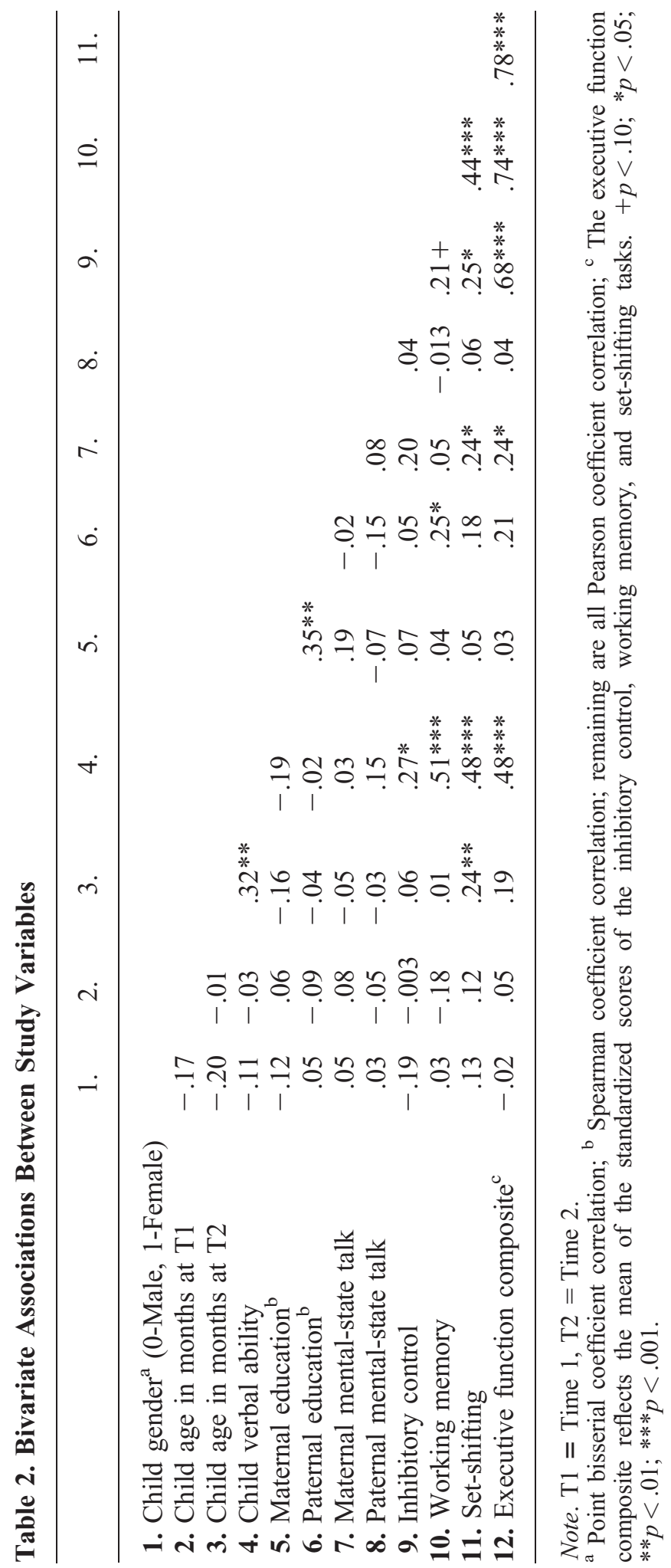


Table 3. Predicting the EF composite

$$
R^{2}\left(\text { Adj. } R^{2}\right)
$$

Control variables

Step 1

Child gender (0-Male, 1-Female)

Step 2

Child age at $\mathrm{T} 2$

Step 3

Maternal education

Paternal education

Step 4

Child verbal ability

Parenting variables

Step 5

Maternal mental-state talk

Paternal mental-state talk

$$
.00(-.01) \quad .02 \quad-.02
$$

$\begin{array}{lll}.04(.01) & 1.32 & .20\end{array}$

$\begin{array}{lll}.07(.01) & 1.18 & .06\end{array}$

.14

$\begin{array}{lll}.36(.31) & 7.51^{* * *} \quad .58^{* * *}\end{array}$

$.40(.34)$

$6.19^{* * *} \quad .21^{*}$

Note. $\mathrm{T} 2=$ Time 2.

${ }^{*} p<.05 ;{ }^{* *} p<.01 ; * * * p<.001$.

the variance. Only maternal mental-state talk proved to be a significant predictor of the EF composite, $\beta=.21, p=.041$, such that children who demonstrated better EF abilities four months before school entry, had mothers who, around one year before, made more references to mental-states. The data revealed that paternal use of mental-state references in interaction with the child was not significantly related to preschoolers' EF composite, $\beta=-.03, p=.780$.

Regression analyses were then computed for each of the EF components, separately. Child gender, age, maternal and paternal education, as well as child verbal ability, were included again in the first four steps of the analysis, followed by maternal and paternal mental-state talk, entered simultaneously in the fifth and final step. As presented in Table 4, and regarding the control variables, child verbal ability emerged as a significant predictor of all the three EF components, specifically inhibitory control, $\beta=.27, p=.032$, working memory, $\beta=.57, p<.001$, and setshifting, $\beta=.44, p<.001$. Child age was also found to be significantly related to set-shifting, $\beta=.38, p=.001$. With respect to the parenting variables, and as expected given the above bivariate correlations, neither maternal nor paternal mental-state talk proved to be significant predictors of inhibitory control or working memory. However, data revealed that maternal use of mental-state references individually and significantly contributed to set-shifting, $\beta=.22, p=.034$, beyond child age and verbal ability. The overall model proved significant, explaining 40 percent of the variance. No significant relations were observed between paternal use of mental-state references in interaction with the child and set-shifting.

\section{Discussion}

The present study aimed to extend current understanding about the role of parenting in the development of EF in preschoolers, most notably by evaluating whether both 
Mental-state Talk and Executive Function in Preschoolers

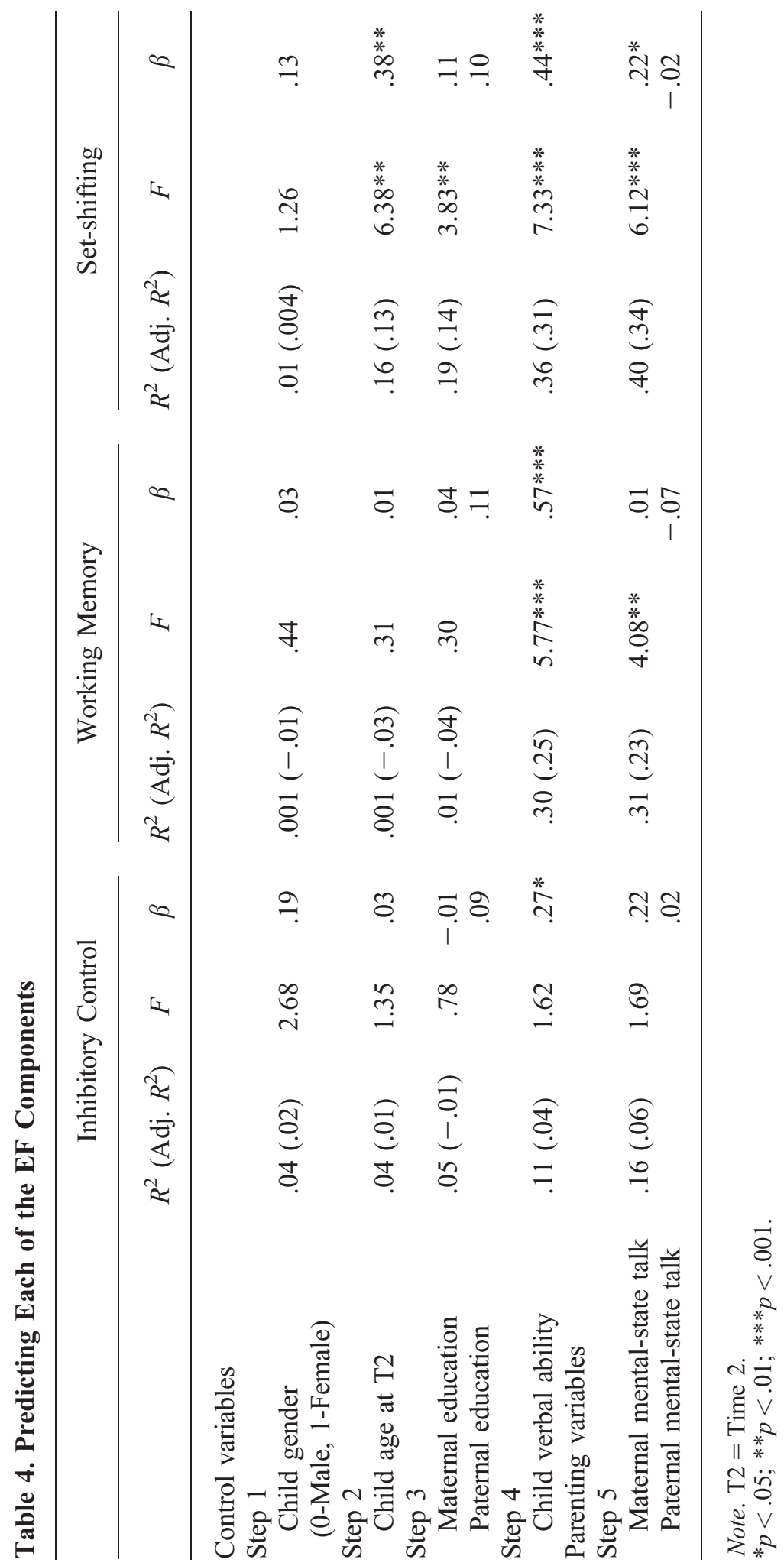


maternal and paternal mental-state talk were prospectively linked to individual differences in child EF skills. Our results support and extend previous literature, namely the work of Bernier and colleagues $(2010,2012)$ performed during toddlerhood, by showing that mothers', but not fathers', use of mental-state references, assessed later on (i.e., during the preschool period), made a significant contribution to the child EF composite. Children experiencing higher quality of parenting during the second preschool year, assessed in terms of maternal talk, were found to have a better overall performance on EF tasks, four months before school entry. Interestingly, when looking at each of the EF components, maternal mental-state talk proved to be a predictor of set-shifting whereas no significant relations emerged with inhibitory control or working memory. These results suggest that mothers' use of mental-state terms may be much more beneficial for the development of children's flexible thinking, than for the other EF components. It is likely that, by supplying children with different mental-state terms, as well as by moving from one mental utterance to another, mothers are, in fact, providing opportunities for children to learn words to manipulate their own thoughts and behavior, and, more specifically, supporting their children's ability to switch back and forth between mental sets, which in turn will aid them in adjusting their behaviors, according to the demands of a given situation. Such results are noteworthy in that they add to a growing body of empirical literature, by showing that the quality of parentingoperationalized herein in its verbal dimension (i.e., the use of mental-state utterances), following Carlson's (2003) conceptualization - forecasts the development of cognitive regulatory abilities, particularly children's shifting abilities, by the end of the preschool period. Interestingly, this constitutes a developmental phase where links between parental mental-state talk and child EF skills have not been yet investigated, even though authors have considered the preschool years as particularly critical for the development of executive competencies (e.g., Garon et al., 2008).

Moreover, the relation between maternal mental-state talk and preschoolers' EF composite and set-shifting remained significant even when child verbal ability was taken into account, which was also found to be a significant predictor of executive skills, explaining, in fact, a large proportion of variance. Such findings are important due to the fact that an accumulating body of research has suggest that better verbal competencies are related to higher EF in young children (Fuhs \& Day, 2011; Müller et al., 2005). Thus, the current study provided preliminary support for the premise that the effects of maternal talk, assessed in terms of the use of mental-state references, on preschoolers' EF occur beyond child verbal competencies. To our knowledge, this is the first study to have examined the prospective relations between parental mental-state talk and EF, while taking preschoolers' verbal ability into account as an important control variable; and, thus, replication is clearly needed. Furthermore, it is worth bearing in mind that no significant associations were found between parental talk and child verbal ability, which is consistent with some (Meins et al., 2003), but not with other studies (Deckner et al., 2006; Fivush et al., 2006). A factor to consider in entertaining reasons for the failure to document such seemingly anticipated associations is that in our own, as well as in Meins and colleagues' (2003) work, the focus was on a specific dimension of parents' talk in interaction with the child - that is, the parents' use of mind-related commentswhereas other research that has documented a link between parents' talk and child verbal ability was focused on more broad, general, features of parent-child 
conversations, including parents' narrative structure, and amount of talk. Such differences across inquiries could account for the variation in the results.

In addition to verbal ability, child age also emerged as a significant predictor of set-shifting. This not surprising result is clearly in line with a recent meta-analytic study, showing that age is a robust predictor of switching performance, but, most importantly, that the magnitude of this effect increases with age during the preschool period (Doebel \& Zelazo, 2015). Interestingly, no significant associations were found between age and inhibitory control or working memory. A possible explanation is that the age range in this study (i.e., all children were between 5 and 6 years at T2) was not wide enough to detect significant associations between age and preschoolers' performance on those two EF components. In fact, this claim is consistent with findings from recent studies, showing no significant differences between 5- and 6-year-olds both in inhibitory control and in working memory (e.g., Roman, Pisoni, \& Kronenberger, 2014; Shaul \& Schwartz, 2014).

In sharp contrast to our findings revealing that maternal talk was related to preschoolers' EF, our hypothesis that paternal use of mental-state comments, while in interaction with the child, would predict executive abilities, along with maternal talk, did not receive empirical support. A possible explanation is that other specific indices of father parenting, beyond fathers' mental-state talk, such as scaffolding and sensitivity (Carlson, 2003), may be more influential for the development of child EF skills. Thus, mother and father may both play a significant role in fostering preschoolers' EF abilities, but in qualitatively different manners. In fact, according to Grossman et al. (2002), fathers' support and sensitivity during play may be particularly relevant for the development of regulatory skills. This claim has been recently supported by Towe-Goodman and colleagues (2014). Their investigation revealed that fathers' parenting sensitivity during play at 24 months predicted EF at three years of age, even after accounting for maternal contributions. The work of Kochanska, Aksan, Prisco, and Adams (2008) is also noteworthy, as they found that the quality of father-child interaction, measured in terms of responsive and cooperative behaviors, was positively related to increased self-regulatory abilities in preschoolers. Furthermore, because our study was performed with children at the end of the preschool period, the issue of whether fathers' mental-state talk is related to child EF in other developmental periods, is yet to be explored.

Moreover, it may also be the case that other parenting contexts - rather than a picture-book reading task with the child, as it was the case in the present studymay be more appropriate to assess the quality of paternal care. Indeed, authors have argued that more challenging face-to-face interactions between children and fathers may afford children with a better opportunity for them to practice their executive abilities (Grossman et al., 2002). Consistent with this claim, investigators have found that fathers tend to use - particularly during such demanding tasks - more action-oriented strategies, which are optimal to promote children's problem-solving competences (e.g., John, Halliburton, \& Humphrey, 2013).

In addition to this possibility, it may also be the case that the picture-book task used in the current study is better in capturing the contribution of maternal parenting. In line with this premise, recall that, in this investigation, mothers and fathers differed in the use of mental-state terms, such that mothers employed more mindminded comments in interaction with the child than fathers. This result is in line with empirical findings, suggesting that mothers adopt more high-level interactive strategies than fathers in such tasks (Schwartz, 2004), and that they tend to talk 
significantly more about internal states with their preschool age children than fathers during a picture-book task (LaBounty et al., 2008). However, whether mothers and fathers show a similar or a different pattern of mental-state talk in their everyday activities with children at home-including in similar booking reading tasks or in more demanding ones or even routines-, and whether maternal and paternal mental-state talk in these more 'ecological' tasks influence the development of preschoolers' EF deserves to be explored in future studies. Differences in the amount of exposure to mothers' and fathers' mental-state language in day-to-day activities may be also accounting for the differences in the influence of each parent on children's EF. In fact, previous research has shown that mothers tend to spend more time in one-to-one interactions with their children than fathers, thus allowing mothers to have more opportunities to acquire and practice skills central to promote child development (Parke, 2002). However, it is unclear whether any of these explanations is responsible for the results reported in this article. Future studies, longitudinal and more ecological in design, are clearly needed.

\section{Limitations and Future Directions}

Although there are a number of strengths to the current study, including the assessment of both maternal and paternal mental-state talk, there are limitations to this research that merit attention. The other two indices of parenting (i.e., scaffolding and sensitivity), argued by Carlson (2003) to be linked to the development of EF, were not measured in the present inquiry. Moreover, it is important to note that, in the present investigation, maternal mental-state talk accounted only for a small proportion of variance in EF. Thereby, incorporating the assessment of all of those parenting indices, with regard to both maternal and paternal care, could provide a more comprehensive view of the development of child EF skills. In addition, information regarding the quality of parental mental-state talk in interaction with the child, as well as preschoolers' EF and verbal ability, were available at only a single point in time, most notably during the second and the last preschool period. Thus, the prospective design of our study did not allow for firm conclusions about directionality, and limits the interpretation of the results. For instance, it was not possible to tell whether mothers' and fathers' use of mind-minded comments were facilitated by earlier child verbal competence or even by children's already-advanced EF. Generalization of the results must be made carefully, and future work should be longitudinal in design, with assessments of the quality of parenting, EF and verbal abilities over the first years of life until the school transition.

\section{References}

Ardila, A., Rosselli, M., Matute, E., \& Guajardo, S. (2005). The influence of the parents' educational level on the development of executive functions. Developmental Neuropsychology, 28, 539-560.

Bernier, A., Carlson, S., Deschênes, M., \& Matte-Gagné, C. (2012). Social factors in the development of early executive functioning: A closer look at the caregiving environment. Developmental Science, 15, 12-24. doi:10.1111/j.1467-7687.2011.01093.x

Bernier, A., Carlson, S. M., \& Whipple, N. (2010). From external regulation to selfregulation: Early parenting precursors of young children's executive functioning. Child Development, 81, 326-339. doi: 10.1111/j.1467-8624.2009.01397.x 
Bibok, M. B., Carpendale, J. M., \& Müller, U. (2009). Parental scaffolding and the development of executive function. New Directions for Child and Adolescent Development, 123, 17-34. doi: 10.1002/cd.233

Blair, C., Granger, D., Willoughby, M., Mills-Koonce, R., Cox, M., Greenberg, M., et al. (2011). Salivary cortisol mediates effects of poverty and parenting on executive functions in early childhood. Child Development, 82, 1970-1984. doi: 10.1111/j.1467-8624.2011.01643.x

Blair, C., \& Ursache, A. (2013). A bidirectional model of executive functions and self-regulation. In K. Vohs \& R. Baumeister (Eds.), Handbook of self-regulation: Research, theory and applications. New York: The Guildford Press.

Blakemore, S. J., \& Choudhury, S. (2006). Development of the adolescent brain: Implications for executive function and social cognition. Journal of Child Psychology and Psychiatry, 47, 296-312.

Brocki, K., \& Bohlin, G. (2004). Executive function in children aged 6 to 13: A dimensional and developmental study. Developmental Neuropsychology, 26, 571-593.

Carlson, S. M. (2003). Executive function in context: Development, measurement, theory, and experience. Monographs of the Society for Research in Child Development, 68 (Serial No. 274, 138-151).

Carlson, S. M. (2005). Developmentally sensitive measures of executive function in preschool children. Developmental Neuropsychology, 28, 595-616. doi: 10.1207/s15326942dn2802_3

Carlson, S. M., Mandell, D. J., \& Williams, L. (2004). Executive function and theory of mind: Stability and prediction from ages 2 to 3. Developmental Psychology, 40, 1105-1122.

Carlson, S. M., \& Schaefer, C. (2012). Executive function scale for early childhood: Test manual. Minneapolis, MN: University of Minnesota.

Clark, C. A., Pritchard, V. E., \& Woodward, L. J. (2010). Preschool executive functioning abilities predict early mathematics achievement. Developmental Psychology, 46, 1176-1191. doi: 10.1037/a0019672

Cuevas, K., \& Bell, M. A. (2010). Developmental progression of looking and reaching performance on the A-not-B task. Developmental Psychology, 46, 1363-1371. doi: 10.1037/a0020185

Davis, H. L., \& Pratt, C. (1995). The development of theory of mind: The working memory explanation. Australian Journal of Psychology, 47, 25-31.

Deckner, D., Adamson, L., \& Bakerman, R. (2006). Child and maternal contributions to shared reading: Effects on language and literacy development. Journal of Applied Developmental Psychology, 27, 31-41. doi: 10.1016/j.appdev.2005.12.001

Diamond, A. (2013). Executive functions. Annual Review of Psychology, 64, 135-168. doi: 10.1146/annurev-psych-113011-143750

Dilworth-Bart, J. (2012). Does executive function mediate SES and home quality associations with academic readiness. Early Childhood Research Quarterly, 27, 416-425. doi: 10.1016/j.ecresq.2012.02.002

Doebel, S., \& Zelazo, P. (2015). A meta-analysis of the Dimensional Change Card Sort: Implications for developmental theories and the measurement of executive function in children. Developmental Review, 38, 241-268. doi: 10.1016/j.dr.2015.09.001

Dunn, L. M., \& Dunn, L. M. (1981). Peabody picture vocabulary test-revised: Form M. Circle Pines, MN: American Guidance Service.

Fivush, R., Haden, C., \& Reese, E. (2006). Elaborating on elaborations: Role of maternal reminiscing style in cognitive and socioemotional development. Child Development, 77, 1568-1588. doi: 10.1111/j.1467-8624.2006.00960.x

Frye, D., Zelazo, P. D., \& Palfai, T. (1995). Theory of mind and rule-based reasoning. Cognitive Development, 10, 483-527. doi: 10.1016/0885-2014(95)90024-1

Fuhs, M., \& Day, J. (2011). Verbal ability and executive functioning development in preschoolers at head start. Developmental Psychology, 47, 404-416. doi: 10.1037/a0021065

Garon, N., Bryson, S., \& Smith, S. (2008). Executive function in preschoolers: A review using an integrative framework. Psychological Bulletin, 134, 31-60. doi: 10.1037/0033-2909.134.1.31

Giedd, J. (2008). The teen brain: Insights from neuroimaging. Journal of Adolescent Health, 42, 335-343. doi: 10.1016/j.jadohealth.2008.01.007

Grossman, K., Grossman, K., Fremmer-Bombik, E., Kindler, H., Scheuerer-Englisch, H., \& Zimmermann, P. (2002). The uniqueness of the child-father attachment relationship: Fathers' sensitive and challenging play as a pivotal variable in a 16-year longitudinal study. Social Development, 11, 301-337. doi: 10.1111/1467-9507.00202 


\section{Joana Baptista, Ana Osório, Eva Costa Martins et al.}

Hammond, S. I., Müller, U., Carpendale, J. I., Bibok, M. B., \& Liebermann-Finestone, D. P. (2012). The effects of parental scaffolding on preschoolers' executive function. Developmental Psychology, 48, 271-281. doi: 10.1037/a0025519

Hughes, C. (2011). Changes and challenges in 20 years of research into the development of executive functions. Infant and Child Development, 20, 251-271. doi: 10.1002/icd.736

Hughes, C., \& Ensor, R. (2011). Individual differences in growth in executive function across the transition to school predict externalizing and internalizing behaviors and children's self-perceived academic success at age 6. Journal of Experimental Child Psychology, 108, 663-676. doi: 10.1016/j.jecp.2010.06.005

Huttenlocher, P. R. (2002). Neural plasticity: The effects of environment on the development of the cerebral cortex. Cambridge, MA: Harvard University Press.

Jenkins, J. M., Turrell, S. L., Kogushi, Y., Lollis, S., \& Ross, H. S. (2003). A longitudinal investigation of the dynamics of mental state talk in families. Child Development, 74, 905-920. doi: 10.1111/1467-8624.00575

John, A., Halliburton, A., \& Humphrey, J. (2013). Child-mother and child-father play interaction patterns with preschoolers. Early Child Development and Care, 183, 483-497. doi: 10.1080/03004430.2012.711595

Kochanska, G., Aksan, N., Prisco, T. R., \& Adams, E. E. (2008). Mother-child and fatherchild mutually responsive orientation in the first 2 years and children's outcomes at preschool age: Mechanisms of influence. Child Development, 79, 30-44. doi: 10.1111/ j.1467-8624.2007.01109.x

Kochanska, G., Murray, K., \& Coy, K. (1997). Inhibitory control as a contributor to conscience in childhood: From toddlers to early school age. Child Development, 68, 263-277.

Kopp, C. (1982). Antecedents of self-regulation: A developmental perspective. Developmental Psychology, 18, 199-214. doi: 10.1037/0012-1649.18.2.199

LaBounty, J., Wellman, H., Olson, S., Lagattuta, K., \& Liu, D. (2008). Mothers' and fathers' use of internal state talk with their young children. Social Development, 17, 757-775. doi: 10.1111/j.1467-9507.2007.00450.x

Landry, S. H., Miller-Loncar, C. L., Smith, K. E., \& Swank, P. R. (2002). The role of early parenting in children's development of executive processes. Developmental Neuropsychology, 21, 15-21.

Lowe, J., Erickson, S.J., MacLean, P., Duvall, S.W., Ohls, R.K., \& Duncan, A.F. (2014). Associations between maternal scaffolding and executive functioning in 3 and 4 years olds born very low birth weight and normal weight. Early Human Development, 90, 587593. doi: 10.1016/j. earlhumdev.2014.07.009

Lundy, B. (2013). Paternal and maternal mind-mindedness and preschoolers' theory of mind: The mediating role of interactional attunement. Social Development, 22, 58-74. doi: $10.1111 /$ sode. 12009

Martins, E., Osório, A., Veríssimo, M., \& Martins, C. (2014). Emotion understanding in preschool children: The role of executive functions. International Journal of Behavioral Development, 40, 1-10. doi: 10.1177/0165025414556096.

Mayer, M. (1969). Frog, where are you? New York: Dial Press.

Mayer, M. (1992). Frog on his own. New York: Puffin.

Meins, E., Fernyhough, C., Wainwright, R., Clark-Carter, D., Gupta, M., Fradley, E., et al. (2003). Pathways to understanding mind: Construct validity and predictive validity of maternal mindmindedness. Child Development, 74, 1194-1211. doi: 10.1111/1467-8624.00601

Meuwissen, A., \& Carlson, S. M. (2015). Fathers matter: The role of father parenting in preschoolers' executive function development. Journal of Experimental Child Psychology, 140, 1-5. doi: 10.1016/j.jecp.2015.06.010

Moriguchi, Y. (2014). The early development of executive function and its relation to social interaction: A brief review. Frontiers in Psychology, 5, 1-6. doi: 10.3389/fpsyg.2014. 00388

Moriguchi, Y., \& Hiraki, K. (2013). Prefrontal cortex and executive function in young children: A review of NIRS studies. Frontiers in Human Neuroscience, 7, 1-9. doi: 10.3389/ fnhum.2013.00867

Müller, U., Zelazo, P.D., \& Imsirek, S. (2005). Executive function and children's understanding of false belief: How specific is the relation? Cognitive Development, 20, 173-189. doi: 10.1016/j.cogdev.2004.12.004 
Parke, R. D. (2002). Fathers and families. In M. Bornstein (Ed.), Handbook of parenting, Vol. 3: Being and becoming a parent (pp. 27-73). Hillsdale, NJ: Erlbaum.

Ponitz, C. C., McClelland, M. M., Matthews, J. S., \& Morrison, F. J. (2009). A structured observation of behavioral regulation and its contributions to kindergarten outcomes. Developmental Psychology, 45, 605-619. doi: 10.1037/a0015365

Rochette, E., \& Bernier, A. (2014). Parenting, family socioeconomic status, and child executive functioning: A longitudinal study. Merrill-Palmer Quarterly, 60, 431-460.

Roman, A., Pisoni, D., Kronenberger, W. (2014). Assessment of working memory capacity in preschool children using the Missing Scan task. Infant and Child Development, 23, 575-587. doi: 10.1002/icd.1849

Ruffman, T., Slade, L., \& Crowe, E. (2002). The relation between children's and mothers' mental state language and theory-of-mind understanding. Child Development, 73, 734-751. doi: 10.1111/1467-8624.00435

Schwartz, J. I. (2004). An observational study of mother/child and father/child interactions in story reading. Journal of Research in Childhood Education, 19, 105-114.

Shaul, S., \& Schwartz, M. (2014). The role of the executive functions in school readiness among preschool-age children. Reading and Writing, 27, 749-768. doi: 10.1007/s11145-013-9470-3

Towe-Goodman, N., Willoughby, M., Blair, C., Gustafsson, H., Mills-Koonce, R., \& Cox, M. (2014). Fathers' sensitive parenting and the development of early executive functioning. Journal of Family Psychology, 28, 867-876. http://dx.doi.org/10.1037/a0038128

Wanless, S., McClelland, M., Acock, A., Ponitz, C., Son, S., \& Lan X., et al. (2011). Measuring behavioral regulation in four societies. Psychological Assessment, 23, 364-378. doi: 10.1037/a0021768

Wiebe, S. A., Espy, K. A., \& Charak, D. (2008). Using confirmatory factor analysis to understand executive control in preschool children: I. Latent structure. Developmental Psychology, 44, 575-587. doi: 10.1037/0012-1649.44.2.575

Wieber, S. A., Sheffield, T. D., Nelson, J. M., Clark, C. A., Chevalier, N., \& Espy, K. A. (2011). The structure of executive function in 3-year-old children. Journal of Experimental Child Psychology, 108, 436-452. doi: 10.1016/j.jecp.2010.08.008

Vallotton, C., \& Ayoub, C. (2011). Use your words: The role of language in the development of toddlers' self-regulation. Early Childhood Research Quarterly, 26, 169-181. doi: 10.1016/j.ecresq.2010.09.002

van de Weijer-Bergsma, E., Wijnroks, L., Boom, J., de Vries, L. S., van Haastert, I. C., \& Jongmans, M. J. (2010). Individual differences in developmental trajectories of A-not-B performance in infants born preterm. Developmental Neuropsychology, 35, 605-621. doi: $10.1080 / 87565641.2010 .508545$

Vygotsky, L. S. (1934/1986). Thought and language. Cambridge, MA: The MIT press.

Zelazo, P. D. (2006). The dimensional change card sort (DCCS): A method of assessing executive function in children. Nature Protocols, 1, 297-301. doi: 10.1038/nprot.2006.46

Zelazo, P. D., \& Carlson, S. M. (2012). Hot and cool executive function in childhood and adolescence: Development and plasticity. Child Development Perspectives, 6, 354-360. doi: $10.1111 / \mathrm{j} .1750-8606.2012 .00246 . x$

Zelazo, P. D., Muller, U., Frye, D., \& Marcovitch, S. (2003). The development of executive function in early childhood. Monographs of the Society for Research on Child Development, 68, vii-137.

\section{Acknowledgments}

This research was supported by Grant COMPETE: FCOMP-01-0124-FEDER-015504 from Fundação para a Ciência e Tecnologia, and the European Regional Development Fund (FEDER) through the European program COMPETE (Operational Programme for Competitiveness Factors) under the National Strategic Reference Framework (QREN) attributed to the research project titled 'Children's socio-emotional-cognitive school readiness: A longitudinal approach to its developmental course during preschool years' (PTDC/PSI-EDD/ 114527/2009; also grant SFRH/BPD/100994/2014 assigned to the first author). The authors are very grateful to the students who helped with data collection. Special thanks go to the children and families who participated in the study. 